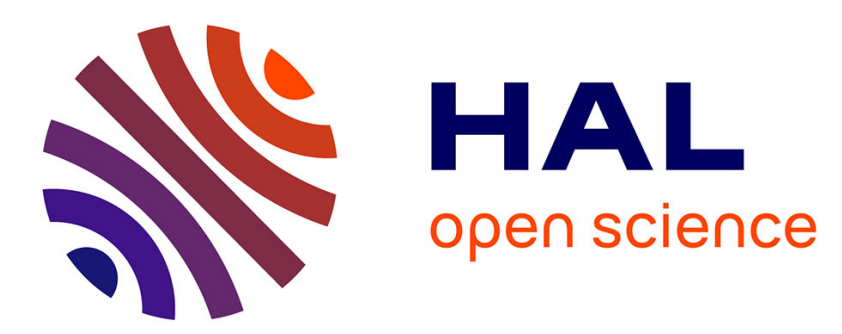

\title{
Insight of a w/o emulsion drop under leidenfrost heating using laser-induced fluorescence optical diagnostics
}

Omar Moussa, Diego Francelino, Dominique Tarlet, Patrizio Massoli, Jérôme Bellettre

\section{- To cite this version:}

Omar Moussa, Diego Francelino, Dominique Tarlet, Patrizio Massoli, Jérôme Bellettre. Insight of a w/o emulsion drop under leidenfrost heating using laser-induced fluorescence optical diagnostics. Atomization and Sprays, 2019, 29 (1), pp.1-17. 10.1615/AtomizSpr.2019029233 . hal-02372826

\section{HAL Id: hal-02372826 \\ https://hal.science/hal-02372826}

Submitted on 26 Feb 2021

HAL is a multi-disciplinary open access archive for the deposit and dissemination of scientific research documents, whether they are published or not. The documents may come from teaching and research institutions in France or abroad, or from public or private research centers.
L'archive ouverte pluridisciplinaire HAL, est destinée au dépôt et à la diffusion de documents scientifiques de niveau recherche, publiés ou non, émanant des établissements d'enseignement et de recherche français ou étrangers, des laboratoires publics ou privés. 
INSIGHT OF A W/O EMULSION DROP UNDER LEIDENFROST HEATING USING LIF OPTICAL DIAGNOSTICS

Omar Moussa, ${ }^{1}$ Diego Francelino, ${ }^{1}$ Dominique Tarlet, ${ }^{1}$ Patrizio Massoli, ${ }^{2}$ \& Jerome Bellettre ${ }^{1, *}$

${ }^{1}$ Laboratoire de Thermique et Energie de Nantes (LTeN) Université de Nantes - CNRS UMR 6607, rue Christian Pauc, Nantes, France

${ }^{2}$ Istituto Motori, Consiglio Nazionale delle Ricerche, Napoli, Italy

*Address all correspondence to: Jerome Bellettre, Laboratoire de Thermique et Energie de Nantes (LTeN) Université de Nantes - CNRS UMR 6607, rue Christian Pauc, Nantes, France, Email: jerome.bellettre@univ-nantes.fr

ABSTRACT: Water-in-oil emulsion droplet may undergo a phenomenon called microexplosion when under strong heating. Micro-explosion can be defined as the atomization of the continuous phase (i.e. oil) by the dispersed droplets (i.e. water) phase change and the volume expansion that is induced. It is established that micro-explosion occurrence is favored by the (partial) coalescence of water droplets before phase change. This process has direct influence on the time evolution of water droplets size. For this purpose, an experimental method based on laser induced fluorescence is set up. It basically consists in adding a fluorescent dye, fluorescein, which is soluble only in water and exciting the emulsion drop by a laser sheet during its heating. The aim is to measure the size evolution of dispersed droplets, but also to target the water droplet triggering the atomization of the emulsion drop, in order to have a better understanding on micro-explosion. The sizing procedure showed promising results. Manual and automatic measurements of the size were compared in order to quantify the average error, which happens to be $<10 \%$. Results show that size of this trigger droplet is not sufficient in order to determine whether an emulsion drop will undergo an optimal atomization. 
KEY WORDS: atomization, biofuel, emulsion, droplet, micro-explosion, LIF, fluorescence, image treatment

NOMENCLATURE

\section{Symbol}

$$
\gamma
$$

$\lambda$

$\mu$

$\rho$

D

HLB

$\mathrm{Oh}$ $\mathrm{T}$

\section{Description}

Interface tension

Wavelength

Viscosity

Density

Diameter

Hydrophilic-lipophilic balance

Ohnesorge number

Temperature

\section{Unit (SI)}

N.m ${ }^{-1}$

m

Pa.s

kg. $\mathrm{m}^{-3}$

m

$\left({ }^{\circ} \mathrm{C}\right)$

\section{INTRODUCTION}

In the last decades, the international scientific community is facing the challenge of the century: the energy independence. Currently, the principal source of energy in the world comes from fossil fuel combustion. Energy overconsumption and the effects induced by the fossil fuel combustion (change of the atmosphere composition with the greenhouse gases associated emissions) led to serious damages to our health and planet (Baker et al., 2007; Solomon et al., 2007).

Interest has been growing in using alternative fuels, like emulsified fuels, as it was demonstrated that adding water in hydrocarbon fuels can reduce the exhaust emissions. According to some authors, the use of these emulsified fuels or water-in-oil (W/O) emulsions can lead to the reduction of NOx, PM, CO and soot emissions (Khan et al., 2014a; Kadota and Yamasaki, 2002; Armas et al., 2005; Marchitto et al., 2018; Hagos et al., 2011; Mura, 2011). Indeed, presence of water inside the oil phase can trigger the phenomenon called "micro- 
explosion”. It can be defined as the secondary atomization of the $\mathrm{W} / \mathrm{O}$ emulsion drop under strong heating, caused by the phase change of water droplets (liquid water into steam). Microexplosion strongly relies on the boiling points difference of oil $\left(200-300{ }^{\circ} \mathrm{C}\right)$ and water $\left(100{ }^{\circ} \mathrm{C}\right)$. The emulsion drop atomization permits a cleaner and complete combustion thanks to the emulsion drop break up, which leads to a better air-fuel mixing (Crookes et al., 1997; Matiello et al., 1992; Nazha and Crookes, 1985; Mizutani et al., 2001; Fuchihata et al., 2007; Geng et al., 2017; Hagos et al., 2017).

Micro-explosion is also characterized by its random aspect: in certain cases, the water embedded droplets phase change is not powerful enough to break the oil phase, leading to a partial atomization called "puffing" (Shinjo et al., 2014; Watanabe et al., 2009). Thus, the phenomenon can be analyzed by introducing a statistical parameter called "occurrence of microexplosion”, defined as the ratio of number of optimal atomization and number of emulsion drops tested (Moussa et al., 2018). Quantitative and qualitative works about parameters influencing micro-explosion showed a great correlation between coalescence (even partial) of water embedded droplets and micro-explosion occurrence (Moussa et al., 2018; Califano et al., 2014; Suzuki et al., 2011; Khan et al., 2016; Mura et al., 2010; Mura et al., 2012; Jarvis et al., 1975; Volkov and Strizhak., 2018; Rashid et al., 2016; Nam, 2012; Khan et al., 2014b; Tarlet et al., 2016; Avidisan and Fatehi, 1988; Morozumi and Saito, 2010; Khan et al., 2018). Coalescence is the process by which two droplets merge, which will inevitably tend to increase the average size of dispersed droplets (Palermo, 1991).

The present work reports the experimental analysis of the heating of water-in-tetradecane emulsion droplets in Leidenfrost regime. Taking into account the space and time scales of both heating and phase change processes, diagnostics based on optical methods are the best solution 
thanks to their high frequency acquisition and the non-intrusive aspect. Laser Induced Fluorescence (LIF) is an optical technique widely used in fluid mechanics and combustion processes allowing imaging, temperature and concentration measurements. It is based on the excitation/emission of light by molecules present in the fluid to be studied or by specific compounds, called dyes or tracers, previously dissolved in it. An experimental test bench, involving high-speed cameras and continuous laser for LIF visualization, has been developed in order to measure the size evolution of the water droplets, and to identify the phenomena occurring inside the emulsion drops.

\section{BACKGROUND}

\subsection{Secondary Atomization Due to Micro-Explosion}

This phenomenon, typical of an emulsified fuel, is due to an abrupt phase change of dispersed droplets, embedded in the continuous phase $\left(100^{\circ} \mathrm{C}\right.$ at atmospheric pressure in the case of water). It consists in the mechanical fragmentation of the emulsified droplet in a very short time (1 ms) (Mura et al., 2010). The released phase change energy is capable to break up the continuous phase (oil) around the water droplet, causing its fragmentation into child droplets. The reduced size of oil droplet in the flame will contribute for an efficient air-fuel mixing, allowing a complete combustion (Matiello et al., 1992).

During the heating process of a W/O emulsion, the droplet temperature will increase and, as a function of several parameters (vaporization temperature, pressure, water content), the water can overpass the saturation temperature without changing the phase thus attaining a metastable state (Mura, 2011). The rupture of this state generates a violent expansion of the vapor phase, as schematically depicted in Fig.1.

\subsection{Occurrence of Micro-Explosion}


Several authors have shown that the micro-explosion phenomena is governed by different parameters as heating temperature (Moussa et al., 2018; Mura et al., 2012), quantity of surfactant or emulsifier (Moussa et al., 2018; Califano et al., 2014; Rashid et al., 2016), or size distribution of water (Moussa et al., 2018; Califano et al., 2014; Nam, 2012; Khan et al., 2014b). Rashid et al., (2016) and Khan et al. (2014b) performed experiments in order to determine the effects of some parameters like surfactant quantity on the occurrence of micro-explosion. It is well known that increasing the surfactant quantity leads to increasing the emulsion droplet stability. Three W/O emulsions are performed with respectively $0.5,1$ and 1.5\% of surfactant (adapted by Khan et al. 2014). In fact, the main effect of surfactant is to reduce the surface tension between the two phases. Thus, it was observed that the aggregation and coalescence rates slowed down and, due to embedded droplet's small size and their inability to coalesce, dispersed droplets vaporize without breaking the oil mother-drop (puffing).

More recently, Moussa et al., (2018) carried out a parametrical study where microexplosion occurrence of $\mathrm{W} / \mathrm{O}$ emulsions was investigated by considering the emulsions physical properties. One of the most interesting results is the evolution of the micro-explosion occurrence with the "internal" Ohnesorge number $\mathrm{Oh}$, which relates the viscous forces to inertial and surface tension forces and its expression is:

$$
O h=\frac{(\mu c)}{\sqrt{\gamma_{W / 0^{\times \rho_{w} \times D}}}}(1)
$$

Where $\mu \mathrm{c}$ is the continuous phase viscosity, $\gamma_{W / O}$ is the interface tension between water and oil, $\rho_{w}$ the water density and D the water droplet average size. We can clearly see, from Fig.2, that the micro-explosion rate is decreasing with Oh. This can highlight the influence of the continuous phase and interface tension.

The configuration where Oh is small (low viscosity, high interface tension and size), 
offers the highest micro-explosion occurrence (between 40-60\%). This is caused by an easier motion of the dispersed droplets through the continuous oil, enhancing water coalescence. Whereas bigger values of Oh (high viscosity, low inertia) prevent the dispersed droplets from moving through the oil, leading to a decreased micro-explosion rate. Generally speaking, a lower viscosity of the continuous phase triggers a successful micro-explosion more easily within industrial applications.

\section{MATERIALS AND METHODS}

\subsection{Emulsion Preparation}

Emulsions are, by definition, the mixture of two non-miscible fluids. This diphasic system presents an interface at its lowest energy level. However, the process of emulsification, which consists of adding mechanical energy, permits the dispersion of one fluid (dispersed phase) in the other (continuous phase) (Fig.3).

In the present study, the dispersed phase is demineralized water. It is favored over tap water because of its relative purity: indeed, tap water may contain impurities that trigger the bubbling too soon during the heating, which can lead to an early puffing (Moussa et al., 2018). Concerning the continuous phase, $n$-tetradecane $\left(\mathrm{C}_{14} \mathrm{H}_{30}\right)$ is chosen for two reasons: it has almost the same physical properties than diesel oil but, unlike it, n-tetradecane is a pure hydrocarbon that can be excited only in the UV band. Thus, it won't affect the LIF visualization based on visible light excitation ( $\lambda=532 \mathrm{~nm}$ in our set up).

Non-ionic surfactant (Span 83) is added in order to prevent an early phase separation between water and oil, by reducing the interface tension and thus enhancing the emulsion stability. Surfactants are characterized by the Hydrophile-Lipophile Balance (HLB) value that should be between 3 and 6 for W/O emulsions (Belkadi et al., 2015). As we can see in Table 1, 
HLB value of Span 83 is 3.7.

The emulsion preparation is performed using a mechanical stirrer at $1500 \mathrm{rpm}$ during 10 minutes, at room temperature in order not to affect the surfactant efficiency and ensure a uniform distribution.

\subsection{Experimental Apparatus}

The Fig.4 represents the experimental set up for the study of the heating of W/O emulsion droplets by means of LIF.

\subsubsection{Heating Device}

Leidenfrost levitation was adopted to suspend and heat the droplets. Fig. 5 presents the geometrical shape of the heat plate and its main components. The droplet holder is made in aluminum and was conceived in circular convex geometry (6 $\mathrm{mm}$ diameter) to trap the droplet during heating process, avoiding at maximum the lateral displacement and, eventually, the droplet fall. A resistive wire is fixed around the droplet holder, and is connected to a power generator. A $80 \mu \mathrm{m}$ K-type thermocouple is placed at the bottom of the drop holder (measurement error of $\pm 1.5^{\circ} \mathrm{C}$ ), and is connected to a PID controller, which allows to measure and regulate the heating temperature. The heat plate temperature is fixed according to previous results presented by Moussa et al., 2018. Indeed the authors found out that the higher the heating temperature is, the higher the micro-explosion rate is (for the same heating configuration). Thus, the temperature is fixed at $500^{\circ} \mathrm{C}$, because it is the highest temperature achievable with the used heating device.

\subsubsection{Optical Acquisition}

As it was previously stated, LIF method is used for the visualization of water embedded droplets. LIF (or PLIF, Planar Laser Induced Fluorescence, being the laser beam reduced to a sheet) is an 
optical, non-intrusive technique allowing the measurements of different properties (species concentration, fluid temperature distribution, imaging...). It involves the dissolution of a fluorescence dye or tracer in a gas or liquid phase and is based on a two-step process: first, the absorption of an incident laser photon at a defined wavelength that leads the tracer molecule to a higher energetic state. Such state is unstable and thus, it results in a photon emission at a different wavelength, moving from an excited to a lower energy state.

The major point is the choice of the proper fluorescent dye. In the present case, Fluorescein was dissolved in the dispersed phase (water). It was chosen over other classical dyes for its very low solubility in oil phases and a complete solubility in water. Indeed, the LIF technique is used in this study in order to create a visual contrast between water and oil phases allowing us to identify water droplets embedded in oil. Fig.6a shows absorption and emission spectrum of Fluorescein.

The W/O emulsion droplet, previously generated with a syringe and put on the heating device, is excited by a $\lambda=532 \mathrm{~nm}$ laser beam (Nd-YAG $2^{\text {nd }}$ harmonic, Spectra Physics). The 4 Watts laser beam is transformed to a planar sheet $(100-200 \mu \mathrm{m})$ by means of a pair of convex lenses (Fig.6b). The fluorescent emitted light is then filtered with a $550 \pm 10 \mathrm{~nm}$ band pass filter and recorded by a Photron V4 Fastcam high speed camera mounted perpendicularly to the beam. It allows the capture of pictures up to 12000 fps with maximum resolution of 1080 x 1024 pixels (Fig.7). In order to ensure the same water droplets size distribution for all the drops tested after emulsification and before heating, the emulsion is continuously stirred. This way, there is no waiting time between the emulsification and the heating, and thus no emulsion stability breakdown.

Regarding the Fluorescein solubility properties, the fluorescent emitted light comes 
essentially from the tracer dissolved in water, meaning that water droplets should appear as bright circular shapes in a dark background that represents the oil phase. The frame rate adopted is between 2000 and $5000 \mathrm{~Hz}$ with an exposure time between 0.08 and $0.125 \mathrm{~ms}$. The frame rate could have been higher, but the chosen parameters ensure a good compromise between number of images to process and their quality.

\subsubsection{Image Processing}

The frames recorded by the high speed camera permits the identification of the water droplets as bright circular shapes. However, in many cases, image treatment is needed in order to ensure the viability of the measurements. The image (a) of the fig. 8 is the original picture recorded. The image (b) corresponds the original image with contrast and brightness adjustments and a background subtraction.

In order to identify and measure water droplets size, an algorithm is built using the Image Processing Toolbox of Matlab. It is based on the Circle Hough Transform (CHT), a reliable technique used for the detection of circles in images where noise, occlusion and varying illumination are occurring. Despite the possible quality improvements using such techniques, occasionally, some unworkable images can be captured. These correspond to a droplet high motion or even to a water phase change, as we can see in the Fig.9.

\section{RESULTS}

The Results section is divided in three parts: the sizing procedure validation, a description of the common behavior observed during the heating of the emulsion drop, and finally, a statistical investigation. This later aims to identify a physical criteria that would explain why an emulsion drop can undergo micro-explosion while another drop from the same emulsion may be subject to puffing. 


\subsection{Sizing Procedure Validation}

The heating of a typically observed W/O emulsion drop is recorded at $2000 \mathrm{fps}$ and with an exposure time of $0.125 \mathrm{~ms}$. The emulsion is composed of $7 \%$ of water and $0.1 \%$ of surfactant. The emulsion drop undergoes an optimal micro-explosion at the end of a heating duration of 950 ms. The water droplets average size is measured for each frame using the procedure described previously (Fig.10)

In order to assess the reliability of the measurements, the results given by the algorithm are compared to manual measurements (orange curve) representing the reference measurements. These measurements basically consists on manually identify bright circular shapes representing water droplets and measure their size. It is found that for $95 \%$ of the frames, the estimated error $e$ between manual $\left(D_{\text {ref }}\right)$ and automatic $\left(D_{\text {auto }}\right)$ measurements of average diameter (Eq.2) is less than $10 \%$, endorsing the use of such a technique in the study. The error comes mainly from the low quality of some frames (Fig.9) and/or the presence of steam within the emulsion drop. We can notice that the average trend of the size evolution is increasing and this is mainly due to the coalescence of water droplets, as it is outlined by the Fig.11. Moreover, the temperature rise is accompanied by the oil phase viscosity decrease that leads to an easier motion of the dispersed droplets and, therefore, their coalescence rate.

$$
e=100 \times \frac{\left|D_{\text {ref }}-D_{\text {auto }}\right|}{D_{\text {ref }}}
$$

Despite the general increase of the water droplets average size, one can notice local decreases of the size evolution, giving the curve an oscillating shape. If the local increase can be explained by coalescence, the fell in the average size can be generated by intermediate puffings represented by black circles in the Fig.10. Some water droplets undergo a phase change to steam without affecting the emulsion drop lifetime (Fig.12). 
It is also important to underline that the images recorded are a 2D-projection of the emulsion drop heating and the phenomena happening inside. By analyzing the movies, it appears that some droplets tend to disappear from the field of view, and reappear few ms later, which can justify the oscillating trend. This can be explained by two factors: first, as it was mentioned, the heating plate has a convex shape in order to maintain the droplet. In this case, the lower area is not visible by the camera (Fig.13). The second explanation concerns the water droplets that are subject to internal convection motions caused by the temperature gradient within the emulsion drop. When the water droplet is not crossing the laser sheet area, it cannot be excited and, therefore it will not be visible (Fig.13).

Concerning multi-disperse droplets size distribution, which is the case for emulsions, the average diameter does not provide a proper measurement of the dispersion, which among other features, are the basis to encourage the coalescence among the dispersed droplets. For these reasons, the evolution of size distribution is investigated in Table 2, between a local minima and maxima. Indeed, coalescence is governed by Laplace Pressure difference between drops. Laplace pressure is inversely related to the size of the drop, which means that droplets of different size are more likely to coalesce than two droplets of same size.

\subsection{Micro-Explosion Characterization}

This section is dedicated to the investigation and the heating of $50 \mathrm{~W} / \mathrm{O}$ emulsion drops. Regarding the random and difficult-to-reproduce aspect of the micro-explosion, it seemed necessary to investigate a large number of $\mathrm{W} / \mathrm{O}$ emulsion drops even if they have the same composition and initial conditions. The emulsion is composed of $5 \%$ of water and $0.1 \%$ of surfactant is selected, heated at $500^{\circ} \mathrm{C}$, with an acquisition frequency of $5000 \mathrm{fps}$ and an exposure time of $0.08 \mathrm{~ms}$. These parameters are fixed in order to ensure a good rate of micro- 
explosion and a workable image quality.

38 over the 50 cases underwent an optimal atomization (76\%) whereas puffings occurred for the 12 remaining drops. Besides, efforts have been undertaken in order to identify the atomization trigger. Nonetheless, in $40 \%$ of the cases (optimal and weak atomization combined), it was not possible to identify the trigger, either because of an unworkable image just before the atomization or the simultaneous presence of two or more potential triggers.

\subsubsection{Common Behavior during the W/O Emulsion Drop Heating}

During the heating of all the emulsion drops, a common behavior is noticed and is depicted by the Fig. 14. The occurrence of swelling and disruptive boiling are clearly identified in all the cases investigated. Intermediate puffings cause the swelling of the emulsion drop, due to the ejection of steam. The spatial temperature gradient created by the strong heating induces a density and surface tension gradient and thus, convective motion of the embedded droplets inside the "mother" drop.

Moreover, the onset of water droplets bubbling is also studied: for each emulsion drop, the time when first bubbles appear is measured. Even if the visualization of steam, using the previously described LIF diagnostic, is not very accurate, occurrence of intermediate puffings and/or emulsion drop swelling can attest the presence of steam inside the emulsion drop. If the reasonable assumption that fluorescein (for a given concentration of $300 \mathrm{mg} / \mathrm{L}$ ) does not affect water properties is made, then presence of vapor states that temperature inside the emulsion drop achieves at least $100^{\circ} \mathrm{C}$. Once the phenomenon was observed for the totality of emulsion drops regardless to the atomization efficiency (micro-explosion or puffing), the curve representing the apparition of the first steam bubble by respect to the heating duration is plotted (Fig.15).

A very interesting linear trend is observed: the first bubbling appears at $20-25 \%$ of 
the emulsion lifetime. So, it is possible to associate the time between bubble apparition and total heating duration. With one information (bubbling or heating duration) it is conceivable to infer about the other and vice-versa. However, as the nucleation sites is random and due to strong convective motion of the dispersed droplets and coalescence, the experimental observation could not be so precise for predicting the dynamics of the droplets neither the most probable region to observe nucleation sites position. To sum up, the typical phenomena happening during the heating of a W/O emulsion drop are represented in the timeline depicted in the Fig.16

\subsection{Atomization Trigger}

In this section, attention is focused on the water droplet that triggers the micro-explosion of the emulsion droplets (called “trigger droplet" in Fig.17). In this experimental campaign, 3 parameters are considered as key points in the occurrence of micro-explosion: size of the trigger droplet, its temperature and position. The LIF visualization permits to measure droplets size and determine their position.

As it was stated previously, the trigger droplet is identified in 30 cases overs 50 (60\%), corresponding to 28 micro-explosions and 2 puffings. For the emulsion drops that underwent puffings, it is more difficult and less accurate to identify trigger droplets principally due to the presence of steam.

Once the identification is done, size of the trigger droplet and the size of an emulsion drop (at the moment of the atomization) are measured. The ratio R (Eq.3) between the size of the trigger droplet and the emulsion drop is then calculated for each case, allowing us to verify if a size threshold is needed. One may notice that the calculation of this ratio takes into account the emulsion drop size, which may differ from one drop to another:

$$
R=\frac{\text { Trigger } \text { water drop radius }}{\text { Emulsion drop radius }}
$$


The Fig.18 represents the ratio R distribution for all the identified trigger droplets. As it can be observed, the size ratio results are heterogeneous. Concerning only the microexplosion cases, one can observe that the results are dispersed [10-58]\% with an average ratio of 26.7\%, which basically means that the trigger droplets size should be in average a quarter of the emulsion drop. Besides, the micro-explosion \#2 occurred with a size ratio of $10 \%$ whereas the Puffing\#1 took place with a bigger ratio (15\%), which also points out the fact that size of the trigger droplet is not a sufficient criteria to determine whether micro-explosion or puffing is occurring. Thereby, another parameter, like temperature of the trigger droplet, affects the release of the water phase change energy, and thus, the atomization efficiency. Indeed, Mura et al. (2010) showed that water embedded droplets may achieve a metastable state up to $170-180^{\circ} \mathrm{C}$, higher than the boiling point.

Position of the trigger droplet is the other parameter investigated. As Tarlet (2008) explained, during phase change of the droplets positioned in the out layer, the water vapor will be ejected together with some quantity of continuous phase, with no ability to disintegrate the emulsion droplet. On the other hand, if the droplet is positioned in the internal layers, the vaporization could induce contact with metastable neighbor droplets inducing a nucleation that causes a complete disintegration.

Coordinates of the trigger droplet center is measured in relation to emulsion droplet center and then, normalized over the emulsion radius. The associated diameter is normalized over the emulsion diameter. Fig.19 depicts a "model” emulsion drop where are reported size and position of all the identified trigger droplets.

It shows that the most populated region is located in the bottom part of the emulsion drop, matching with sedimentation effects, encouraged by coalescence and density difference of the 
two phases. However, two of the smallest droplets $\left(\mathrm{R}_{1}=12 \%, \mathrm{R}_{2}=13 \%\right)$ are located at the upper part at the moment of their phase change. This is mainly due to the convection motions that are counteracting the effects of gravity for such small sizes. In agreement with the previous discussion it can be also noted that when puffing and not micro-explosion was the dominant effect, the trigger droplets are located close to the surface of the emulsion droplet.

\section{CONCLUSION}

This experimental campaign is motivated to grant additional quantitative data, aiming to better understand the micro-explosion phenomenon. Given the samples small scales of space and time, non-intrusive techniques like optical diagnostics are favored for providing an insight of the W/O emulsion drop heating. The experimental conditions presented in this paper are aiming to study the behavior of one single droplet under Leidenfrost effect. These conditions may differ from real industrial spray applications, but the results of this study can be used for modelling validation and numerical simulations of real combustion of W/O emulsion sprays.

Water embedded droplets size is measured thanks to an experimental method based on LIF visualization. The experimental apparatus capability (high frequency images acquisition) and the homemade algorithms are settled to improve image quality and data extraction in a relative short processing time, leading up to satisfactory results when compared to manual results.

Experimental investigations were also carried out on a large number of samples, in order to better visualize and understand the phenomena happening during the heating of a W/O emulsion drop, but also to identify physical criteria to distinguish between optimal and weak atomization. In that regard, size and position of trigger droplets were noted. Future work should focus on the temperature measurements of the water embedded droplets, using two color LIF. Indeed this method can be complementary to the sizing procedure described in this paper, and it is based on 
the temperature dependency of the fluorescent emitted light intensity.

\section{ACKNOWLEDGMENT}

The authors thank the Region Pays de la Loire (Chaire Connect Talent ODE) for the financial support of this work.

\section{REFERENCES}

Armas, O., Ballesteros, R., Martos, F.J., and Agudelo J.R., Characterization of Light Duty Diesel Engine Pollutant Emissions Using Water- Emulsified Fuel, Fuel, vol. 84, no. 8, pp. 1011-1018, 2005.

Avidisian, C.T. and Fatehi, M., An Experimental Study of the Leidenfrost Evaporation Characteristics of Emulsified Liquid Droplets, Int. J. Heat Mass Transf., vol. 31, no. 8, pp. 689692, 1988.

Barker, T., Bashmakov, I., Bernstein, L., Bogner, J., Bosch, P., Dave, R., Davidson, O., Fisher, B., Grubb, M., Gupta, S., and Halsnæs, K., Climate change 2007- Summary for Policymakers: Working Group III Contribution to the Fourth Assessment Report of the IPCC, vol. 4, Cambridge University Press, 2007.

Belkadi, A., Étude Expérimentale du Fractionnement Liquide-Liquide en Micro-Canaux pour la Production en Continu de Biodiesels Emulsionnés, PhD, University of Nantes, 2015.

Califano, V., Calabria, R., and Massoli, P., Experimental Evaluation of the Effect of Emulsion Stability on Micro-Explosion Phenomena for Water-in-Oil Emulsions. Fuel, vol. 117, no. A, pp. 87-94, 2014.

Crookes, R.J., Kiannejad, F., and Nazha, M.A.A., Systematic Assessment of Combustion Characteristics of Biofuels and Emulsions with Water for Use as Diesel Engine Fuels, Energy Conversion Manage., vol. 38, nos. 15-17, pp. 1785-1795, 1997. 
Fuchihata, M., Takeda, S., and Ida, T., The Effect of Water Content Diameter on the Structure of Light Oil-Water Emulsion Spray Flames, ASME-JSME Thermal Eng. Summer Heat Transf. Conf., vol. 1, pp. 601-604, 2007.

Geng, P., Cao, E., Tan, Q., and Wei, L., Effects of Alternative Fuels on the Combustion Characteristics and Emission Products from Diesel Engines: A Review, Renewable Sustainable Energy Rev., vol. 71, pp. 523-534, 2017.

Hagos, F.Y., Aziz, A.R.A., and Tan, I.M., Water-in-Diesel Emulsion and Its Micro-Explosion Phenomenon-Review, IEEE 3rd Int. Conf. on Communication Software and Networks, pp. 314318, 2011.

Hagos, Y., Ali, O.M., Mamat, R., and Abdullah, A.A., Effect of Emulsification and Blending on the Oxygenation and Substitution of Diesel Fuel for Compression Ignition Engine, Renewable Sustainable Energy Rev., vol. 75, pp. 1281-1294, 2017.

Jarvis, T.J., Donohue, M.D, and Katz, J.L., Bubble Nucleation Mechanisms of Liquid Droplets Superheated in Other Liquids, J. Colloid Interface Sci., vol. 50, pp. 359-368, 1975.

Kadota, T. and Yamasaki, H., Recent Advances in the Combustion of Water Fuel Emulsion, Prog. Energy Combustion Sci., vol. 28, no. 5, pp. 385-404, 2002.

Khan, Y.M., Abdul Karim, Z.A., Hagos, F.Y., Aziz, A.R.A., and Tan, I.M., Current Trends in Water-in-Diesel Emulsion as a Fuel, Sci. World J., vol. 17, Article ID 527472, 2014.

Khan, Y.M., Rashid, A.A., Abdul karim, Z.A., and Tan, I.M., Experimental Investigation of Micro-Explosion Occurrence in Water in Diesel Emulsion Droplets during the Leidenfrost Effect, Energy Fuels, vol. 28, no. 11, pp. 7079-708, 2014.

Khan, Y.M., Abdul Karim, Z.A., Rashid, A.A., Heikal, M., and Crua, C., Puffing and MicroExplosion Behavior of Water-in-Pure Diesel Emulsion Droplets during Leidenfrost Effect, 
Combustion Sci. Technol., vol. 187, no. 7, pp. 1186-1197, 2016.

Khan, Y.M., Abdul Karim, Z.A., Rashid, A.A., and Tan, I.M., A Case Study on the Influence of Selected Parameters on Micro-Explosion Behavior of Water in Biodiesel Emulsion Droplets, J. Energy Resources Technol., vol. 139, pp. 1-10, 2017.

Marchitto, L., Calabria, R., Tornatore, C., Bellettre, J., Massoli, P., Montillet, A., and Valentino, G., Optical Investigations in a CI Engine Fueled with Water in Diesel Emulsion Produced through Microchannels, Experimental Thermal Fluid Sci., vol. 95, pp. 96-103, 2018.

Matiello, M., Cosmai, L., Beretta, F., Pistone, L., and Massoli, P., Experimental Evidences for Micro-Explosion in Water/Fuel Oil Emulsion Flames Inferred by Laser Light Scattering, 24th Symposium on Combustion, The Combustion Institute, pp. 1573-1578, 1992.

Mizutani, Y., Fucchihata, M., and Murakoa, M., In Situ Observation of Micro-Explosion of Emulsion Droplets in Spray Flames. Atomization Sprays, vol. 11, no. 5, pp. 521-532, 2001.

Morozumi, Y. and Saito, Y., Characteristics of Auto-Ignition and Micro-Explosion Behavior of a Single Droplet of Water-in-Fuel, Energy Fuels, vol. 24, pp. 1854-1859, 2010.

Moussa, O., Tarlet, D., Massoli, P., and Bellettre, J., Parametric Study of the Micro-Explosion Occurrence of W/O Emulsions, Int. J. Thermal Sci., vol. 133, pp. 90-97, 2018.

Mura, E., Josset, C., Loubar, K., Huchet, G., and Bellettre, J., Effect of Dispersed Water Droplet Size in Micro-Explosion Phenomenon for Water in Oil Emulsion, Atomization Sprays, vol. 20, no. 9, pp. 791-799, 2010.

Mura, E., Contribution à l'étude de la Micro-Explosion d'une Goutte d'émulsion d'eau dans l’huile : Impact de la Granulométrie de la Phase Dispersée, PhD, University of Nantes, 2011.

Mura, E., Massoli, P., Josset, C., Loubar, K., and Bellettre, J., Study of the micro-explosion temperature of water in oil emulsion droplets during the Leidenfrost effect, Experimental 
Thermal Fluid Sci., vol. 43, pp. 63-70, 2012.

Nam, H., An Experimental Investigation of Micro-explosion in Emulsified Vegetable-Methanol Blend, PhD, University of Texas, 2012.

Nazha, M.A.A. and Crookes, R.J., Effect of Water Content on Pollutant Formation in a Burning Spray of Water-in-Diesel Fuel Emulsion, Int. Symposium Combustion, vol. 20, no. 1, pp. 20012010, 1985.

Palermo, T., Le Phénomène de Coalescence. Etude Bibliographique, Revue de l'Institut Français du Pétrole, vol. 46, pp. 325-360, 1991.

Rashid, A.A., Tan, I.M., Abdul karim, Z.A., and Khan, Y.M, Experimental Study on Influence of Surfactant Dosage on Micro Explosion Occurrence in Water in Diesel Emulsion, Appl. Mech. Mater., vol. 819, pp. 287-291, 2016.

Shinjo, J., Xia, J., Ganippa, L.C., and Megaritis, A., Physics of Puffing and Micro-Explosion of Emulsion Fuel Droplets, Physics Fluids, vol. 26, no. 10, pp. 103-302, 2014.

Solomon, S., Qin, D., Manning, M., Averyt, K., and Marquis, M., Climate Change 2007-the Physical Science Basis: Working Group I Contribution to the Fourth Assessment Report of the IPCC (Vol. 4), Cambridge University Press, 2007.

Suzuki, Y., Harada, T., Watanabe, H., Shoji, M., Matsushita, Y., Aoki, H., and Miura, T., Visualization of Aggregation Process of Dispersed Water Droplets and the Effect of Aggregation on Secondary Atomization of Emulsified Fuel Droplets, Proc. Combustion Institute, vol. 33, no. 2, pp. 2063-2070, 2011.

Tarlet, D., Contribution à la Combustion des Emulsions de l'eau dans le Fioul Lourd, PhD, École Nationale Supérieure des Mines de Paris, 2008.

Tarlet, D., Josset, C. and Bellettre, J., (2016) Comparison between Unique and Coalesced Water 
Drops in Micro-Explosions Scanned by Differential Calorimetry, Int. J. Heat Mass Transf., vol. 95, pp. 689-692, 2016.

Volkov, R.S. and Strizhak, P.A., Using Planar Laser Induced Fluorescence to Explore the Mechanism of the Explosive Disintegration of Water Emulsion Droplets Exposed to Intense Heating, Int. J. Thermal Sci., vol. 127, pp. 126-141, 2018.

Watanabe, H., Harada, T., Matsushita, Y., Aoki, H., and Miura, T., The Characteristics of Puffing of the Carbonated Emulsified Fuels, Int. J. Heat Mass Transf., vol. 52, pp. 3676-3684, 2009.

TABLE 1: Physical properties of the fluids used

\begin{tabular}{|c|c|c|c|c|}
\cline { 2 - 5 } \multicolumn{1}{c|}{} & $\boldsymbol{\mu}$ & $\boldsymbol{\rho}$ & Boiling Temp & HLB \\
\cline { 2 - 5 } \multicolumn{1}{c|}{} & $\mathbf{m P a . s}$ & $\mathbf{~ k g . m}^{-3}$ & ${ }^{\circ} \mathbf{C}$ & - \\
\hline Tetradecane & 2,13 & 762 & 254 & - \\
\hline Span 83 & 1500 & 9,4 & - & 3.7 \\
\hline Water & 1 & 1000 & 100 & - \\
\hline
\end{tabular}

TABLE 2: Size distribution evolution

\begin{tabular}{|c|c|c|c|}
\hline $\begin{array}{l}\text { Time } \\
\text { (ms) }\end{array}$ & Image & Diameter distribution & Comments \\
\hline 222.75 & & \begin{tabular}{l|l|l}
35 & Ave. Diameter $=117.2 \mu m$ \\
30 & \\
25 & \\
15 & \\
10 & \\
5 &
\end{tabular} & $\begin{array}{l}\text { Narrow distribution with } 75 \% \text { of } \\
\text { the droplets with diameter }<120 \\
\mu \mathrm{m}\end{array}$ \\
\hline 243.87 & & $\begin{array}{c}35 \\
30 \\
25 \\
20 \\
25 \\
10 \\
10 \\
5 \\
0 \\
0\end{array}$ & $\begin{array}{l}\text { The droplets diameter distribution } \\
\text { is getting wider with the } \\
\text { apparition of intermediate and big } \\
\text { size droplets }\end{array}$ \\
\hline
\end{tabular}




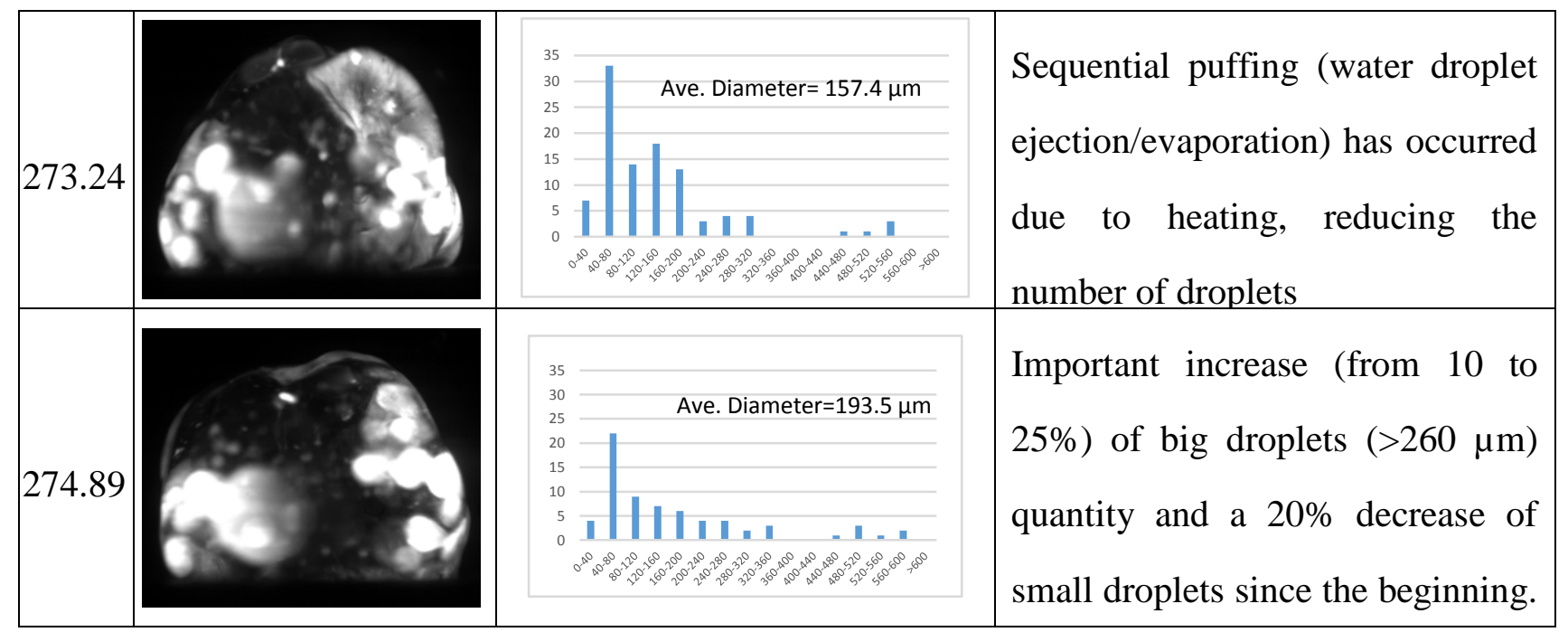

FIG. 1: Micro-explosion process

FIG. 2: Micro-explosion occurrence as a function of Oh

FIG. 3: Emulsification process

FIG. 4: Experimental apparatus- A: High speed camera, B: Beam stopper, C: Heat plate, D:

Optical lenses, E: continuous laser, F: Acquisition computer

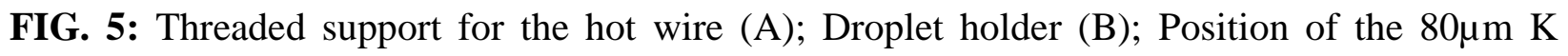
thermocouple (C).

FIG. 6: (a)Excitation and emission spectrum of Fluorescein; (b)Planar laser sheet visualization

FIG. 7: Scheme of the optical apparatus

FIG. 8: Original image recorded (a), Pre-treated image (b), Processed image (c)

FIG. 9: Low quality image due to intermediate puffing

FIG. 10: Average size evolution of water embedded droplets

FIG. 11: Coalescence event recorded

FIG. 12: Phase change of an embedded water droplet (intermediate puffing) [ms]

FIG. 13: Schematic view of the heat plate convex shape and the water convection motion

FIG. 14: Common behavior of W/O emulsion droplets during their heating 
FIG. 15: Correlation between heating duration and moment of vapor bubbles formation FIG. 16: Lifetime of W/O emulsion drop during its heating

FIG. 17: Identification of the trigger droplet (inter frame $=0.2 \mathrm{~ms}$ )

FIG. 18: Size ratio for all 30 identified cases

FIG. 19: Position of trigger droplets 

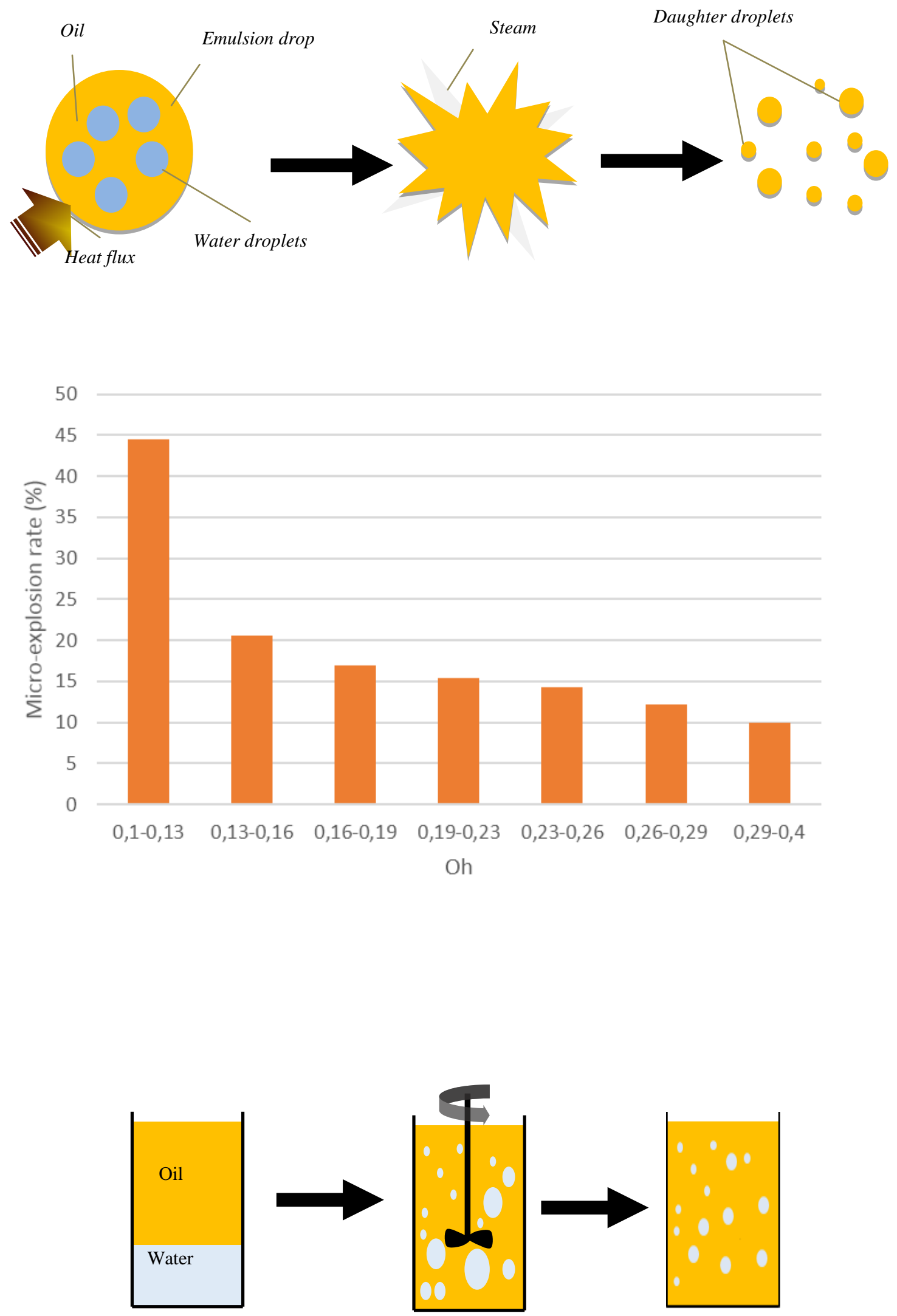

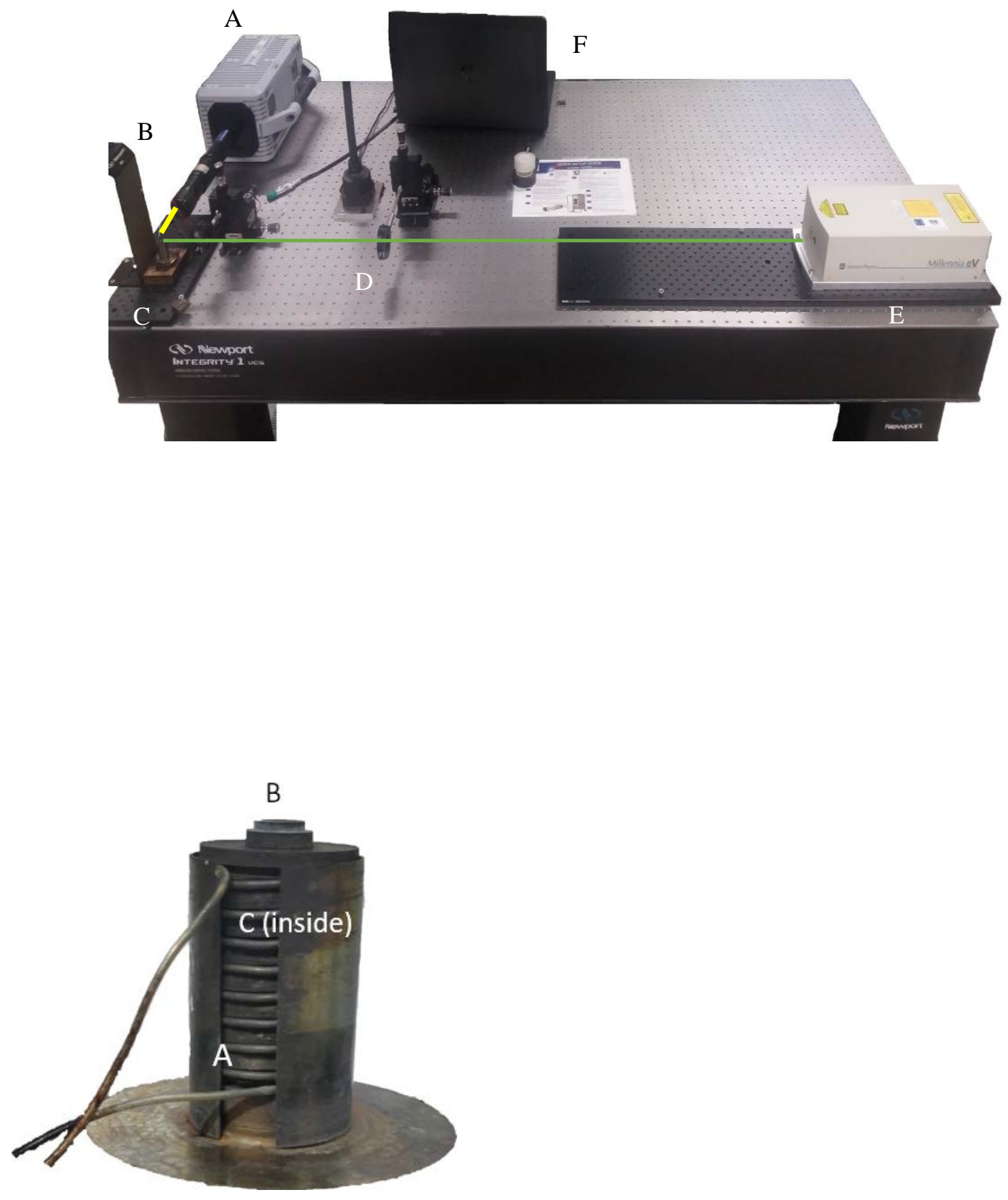

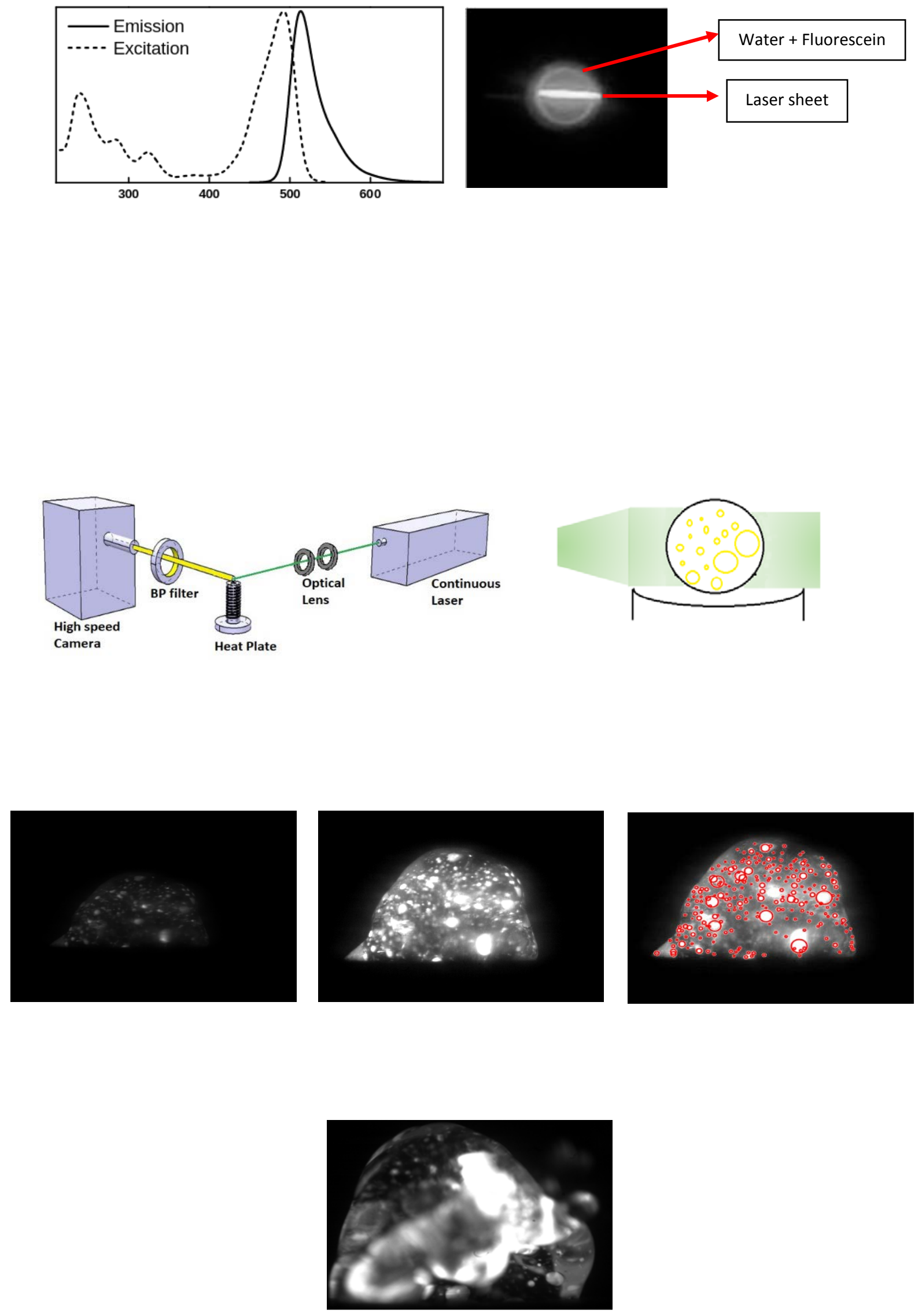

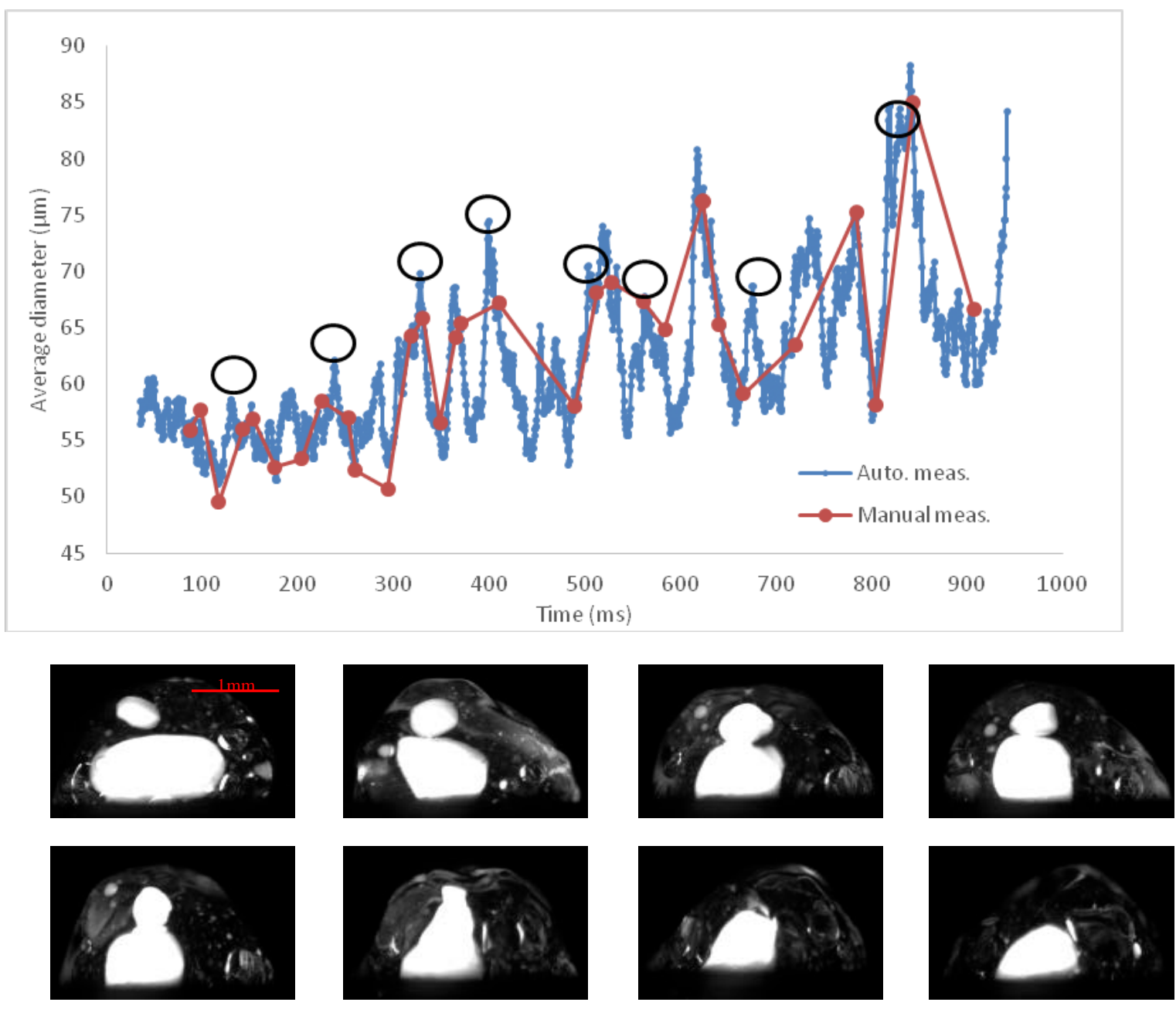

375.5

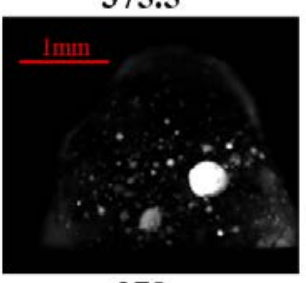

378

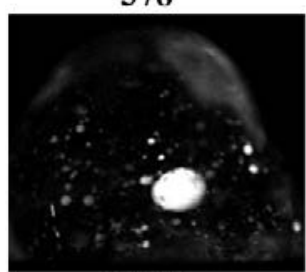

380.5

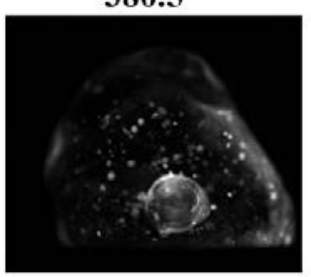

376

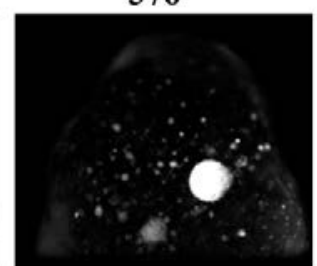

378.5

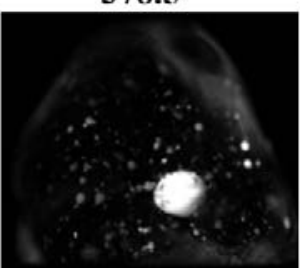

381

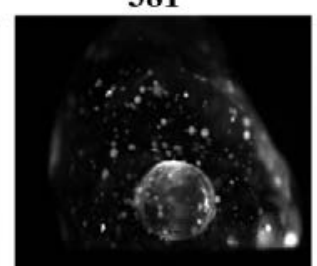

376.5

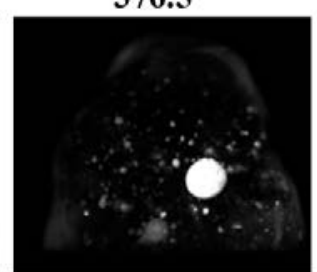

379

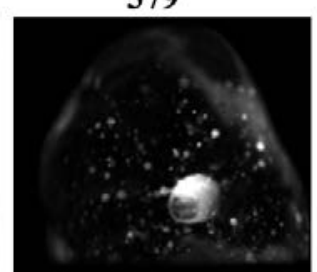

381.5

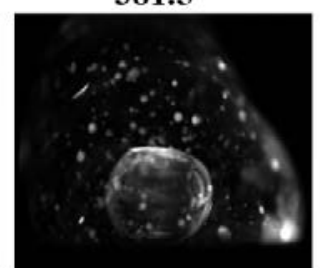

377

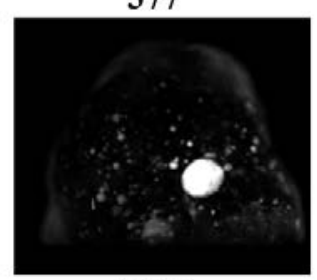

379.5

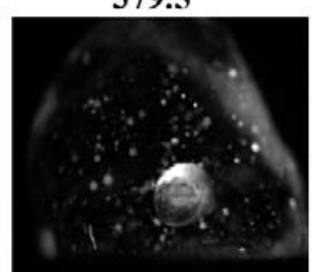

382

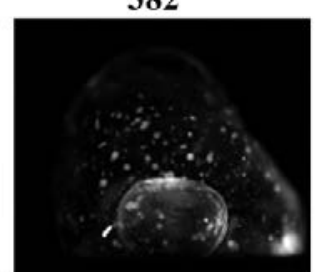

377.5

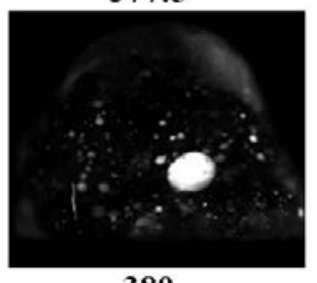

380

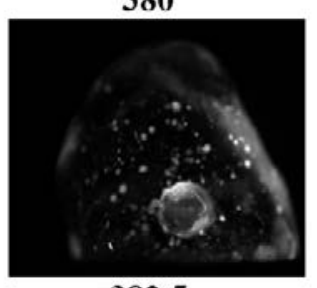

382.5

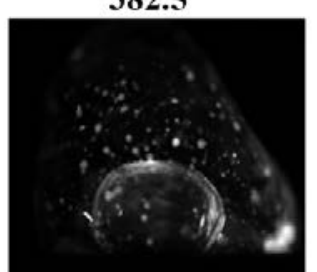



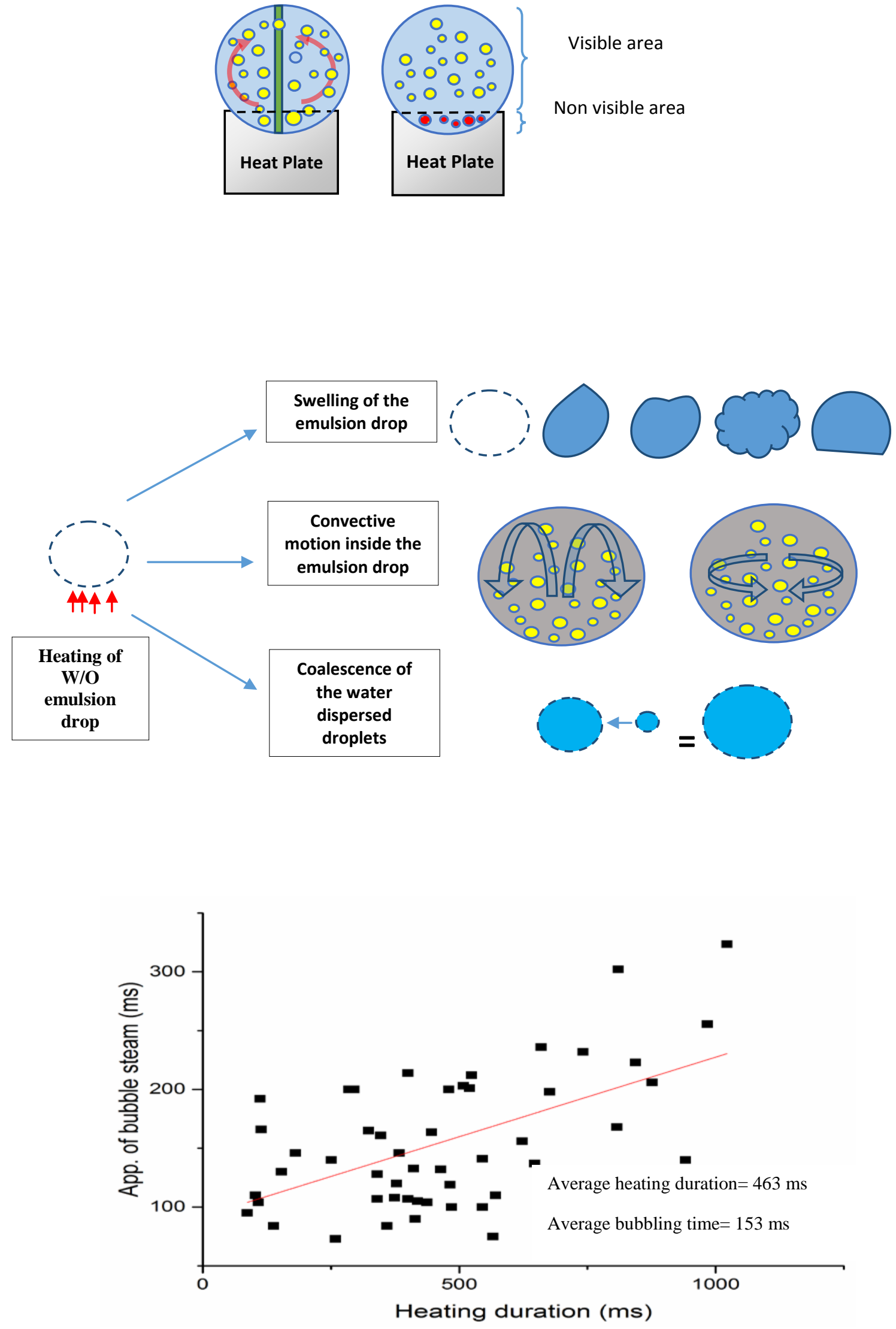
First bubbling $\left(T \circledast 100^{\circ} \mathrm{C}_{s} t=0.2 t_{\text {end }}\right)$
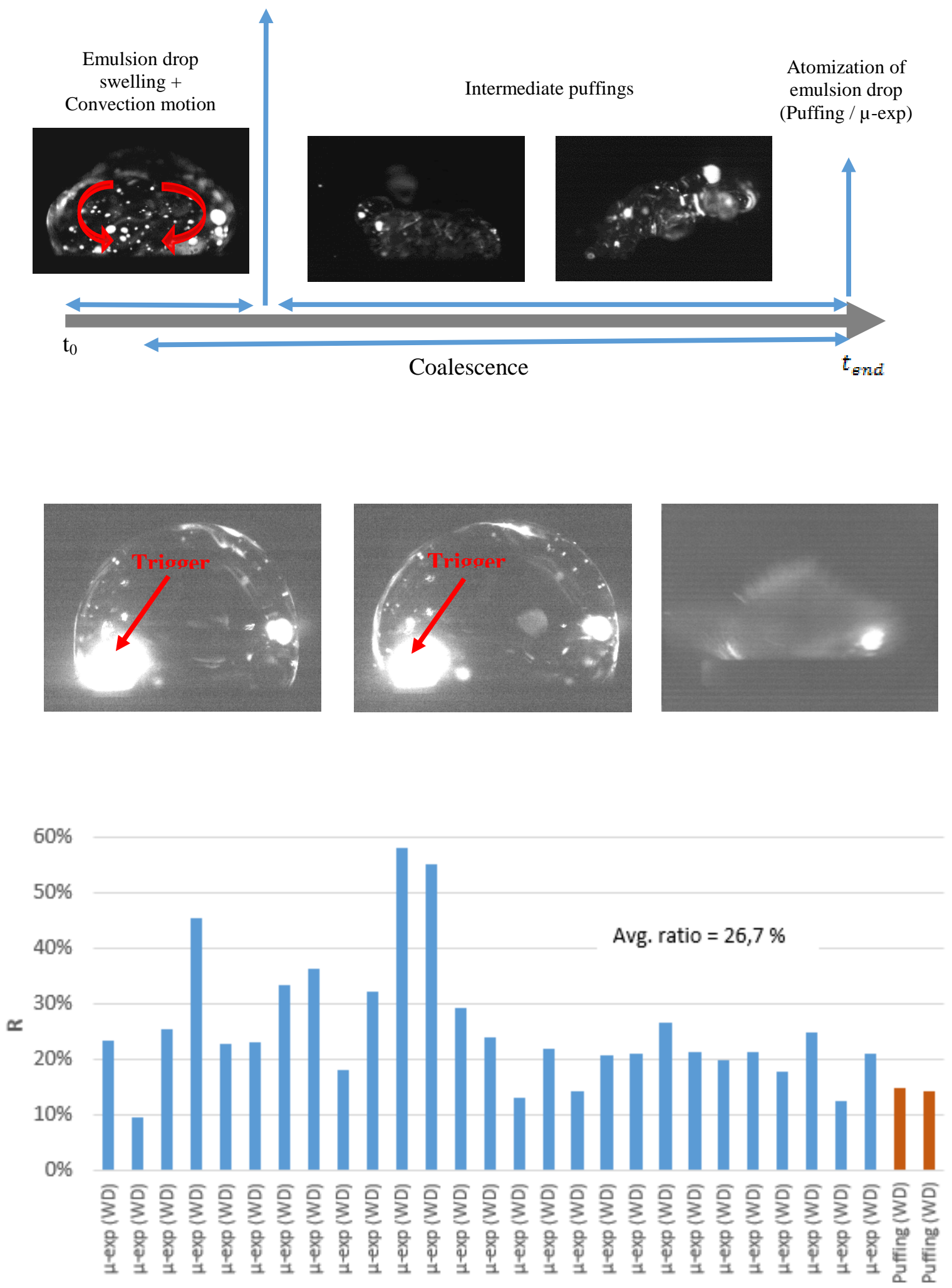


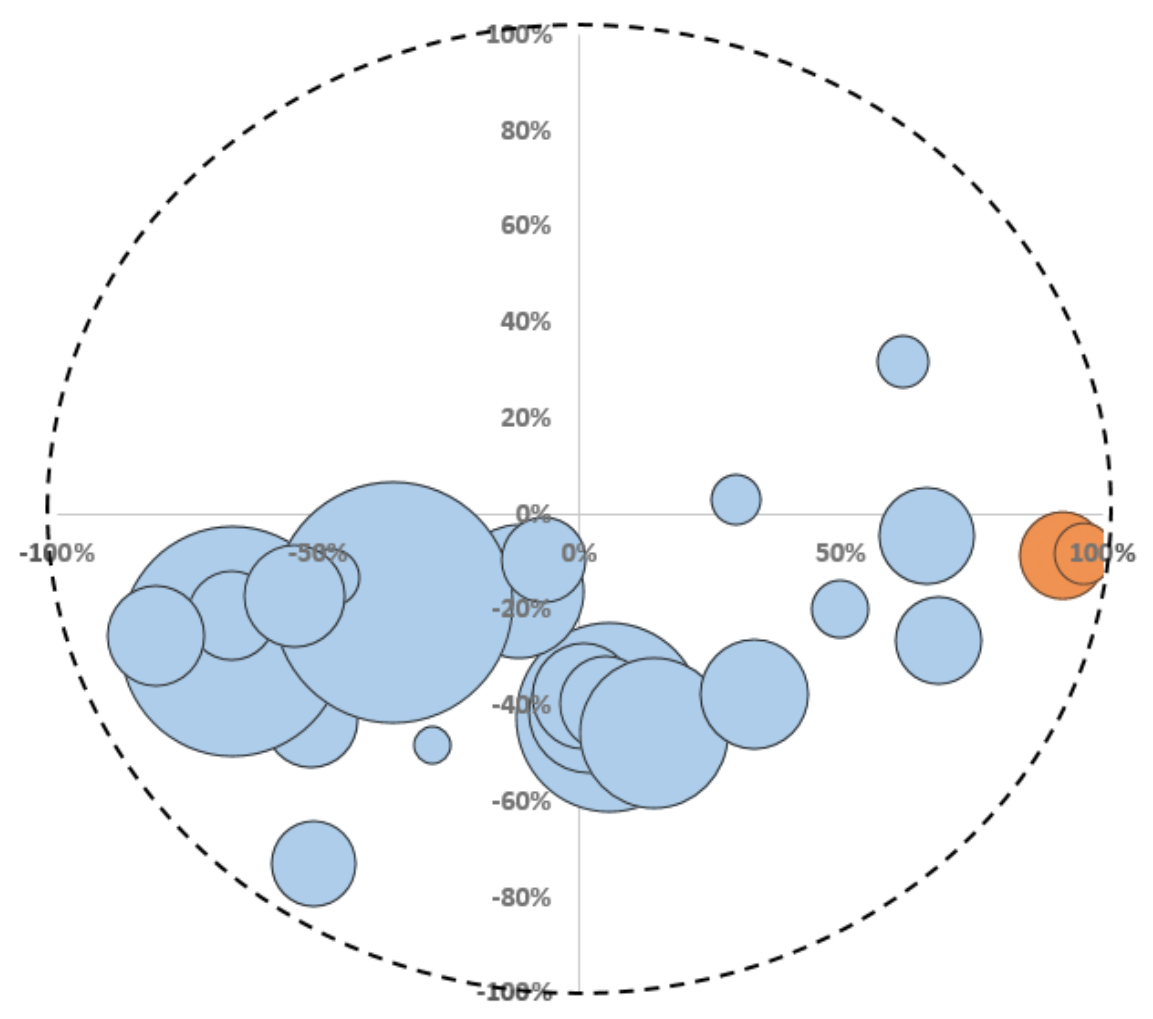

O Micro Explosion

O Puffing 